are of relatively considerable antiquity, and represent the results of geological activity, including an epoch of low temperature, in eastern and southern England.

\section{Current Science}

Wrre the publication of its July issue, our Indian contemporary, Current Science, enters upon its fifth year. Founded to supply an obvious need in the scientific renaissance of India, Current Science is almost unique in that its editor is assisted by a board comprising the majority of the best-known Indian men of science. The July issue contains much of interest not only to India but also to the West. The leading article comments on the inauguration, by his Excellency the Viceroy, of a Nutrition Advisory Committee. The outstanding investigations of Sir Robert McCarrison in Coonoor have in recent years focused the attention of Indian public opinion upon the importance of adequate feeding for national efficiency. Inadequate nutrition, combined in many areas with endemic malaria, is known to be the cause of the poor physique of many classes. The Royal Society is now assisting in the investigation of the intricate problems of malaria control, and will doubtless co-operate with this new Advisory Committee. Another article in the July issue, of more than local interest, is the summary of a lecture given by Prof. Birbal Sahni on the Karewas of Kashmir, where the geology of the Karewas series in the Himalayas is discussed from the point of view of the botanist. We congratulate the editor of Current Science on the high standard of the journal, which, if maintained, ensures its continued success.

\section{Philosophy and Quantum Theory}

If philosophy is, as Descartes claimed, the 'universal science', it should be able to assimilate all new discoveries in the special sciences. There was not much difficulty in dealing with classical physics. When the theory of relativity was put forward, it was soon found that philosophical ideas could be rearranged to find it a place, and even a welcome, but what is to be the attitude to a theory which denies continuity and determinism ? An attempt, admittedly incomplete, to answer these questions has been made by R. Dugas ("La méthode dans la mecanique des quanta". Actualités scientifiques et industrielles, 283. Paris : Hermann et Cie., 1936). Following Meyerson, complete indeterminism is rejected, and replaced by aggregates ruled by laws of probability. If there is no law, there is no science. Other difficulties arise when we try to discover the basis of Schrodinger's equation. Are we to say that our equations know more than we do, and that, without understanding them, we can rely upon them to furnish the correct results? Are we to believe in panmathesis, and in a universe in which electrons and matter have no real existence, but are merely names for mathematical symbols ? The trouble with questions such as these is that all the available evidence appears to point to the conclusions that are repugnant to common sense.

\section{Photomicrographic Reproduction of Scientific Papers}

Following on the formation of the Documentation Division of Science Service, a programme of testing mechanical methods of applying photomicrographic duplication of scientific literature is being developed, including a camera for copying upon $35 \mathrm{~mm}$. film, supplementary apparatus such as a book holder for the camera, film container, etc., a reading machine, microfilm viewer, projection printer, and developing and processing apparatus for $35 \mathrm{~mm}$. microfilm and paper projection points. Procedure has already been developed for the publication of scientific material otherwise unable to receive publication in full. Editors of journals or institutions deposit typescripts of those papers or portions of papers which they are unable to publish promptly or completely. With an abstract or summary, they publish a statement that additional matter, illustrations, tables, etc., are available on request from Science Service if the document number is stated and the price remitted. The document is assigned a number by Science Service and on receipt it is photographed on $35 \mathrm{~mm}$. film master negative. The original document is then deposited elsewhere as a safeguard. The photomicrographic duplication is economical when up to twenty-five copies at a time are required and has the further advantage that the document is continuously in print as the negative can be used to supply a copy on demand at any time.

THE relation of microfilms or photo-copies prepared in this way to priority in scientific discoveries has been raised. Opinion is expressed in a note issued by Science Service that microfilm or photo-copy publication is a printed publication in the true sense, and that by considerably reducing the time between the submission of a paper to a journal and the date of publication of the discovery announced therein, this type of publication will be of great assistance in eliminating controversies such as have arisen in the past concerning individual claims for priority in making discoveries. If any doubt exists as to whether photomicrographic publication is a 'printed publication', it is urged that this doubt could be removed by scientific societies merely agreeing among them. selves that, in so far as priority in their fields is concerned, photomicrographic publication should be accorded the same weight and effect as publication in a printed journal.

\section{Wind Erosion in South Australia}

WIND erosion is becoming an increasing danger in the semi-arid regions which form the world's chief granaries. In North America, the Argentine and to a less extent in Russia, the fertile prairie soils are rapidly being swept away as the result of destroying the original grass cover. A similar fate is overtaking vast pastoral regions in South Australia, due to overstocking. The gravity of the situation is revealed in a note by F. N. Ratcliffe, received from the Commonwealth Council for Scientific and In. dustrial Research. The worst erosion has been in the 'bush' country, where twelve drought years have so 